\title{
Reduced Expression of the NMDA Receptor-Interacting Protein SynGAP Causes Behavioral Abnormalities that Model Symptoms of Schizophrenia
}

\author{
Xiaochuan Guo', Peter J Hamilton ${ }^{2,4}$, Nicholas J Reish',3, J David Sweatt', Courtney A Miller' and \\ Gavin Rumbaugh*,1,2
}

'Department of Neurobiology and Evelyn F. MCKnight Brain Institute, The University of Alabama at Birmingham, Birmingham, AL, USA; ${ }^{2}$ UAB Summer Program in Neuroscience (SPIN); ${ }^{3}$ UAB Medical Scientist Training Program (MSTP)

\begin{abstract}
Abnormal function of NMDA receptors is believed to be a contributing factor to the pathophysiology of schizophrenia. NMDAR subunits and postsynaptic-interacting proteins of these channels are abnormally expressed in some patients with this illness. In mice, reduced NMDAR expression leads to behaviors analogous to symptoms of schizophrenia, but reports of animals with mutations in core postsynaptic density proteins having similar a phenotype have yet to be reported. Here we show that reduced expression of the neuronal RasGAP and NMDAR-associated protein, SynGAP, results in abnormal behaviors strikingly similar to that reported in mice with reduced NMDAR function. SynGAP mutant mice exhibited nonhabituating and persistent hyperactivity that was ameliorated by the antipsychotic clozapine. An NMDAR antagonist, MK-80I, induced hyperactivity in normal mice but SynGAP mutants were less responsive, suggesting that NMDAR hypofunction contributes to this behavioral abnormality. SynGAP mutants exhibited enhanced startle reactivity and impaired sensory-motor gating. These mice also displayed a complete lack of social memory and a propensity toward social isolation. Finally, SynGAP mutants had deficits in cued fear conditioning and working memory, indicating abnormal function of circuits that control emotion and choice. Our results demonstrate that SynGAP mutant mice have gross neurological deficits similar to other mouse models of schizophrenia. Because SynGAP interacts with NMDARs, and the signaling activity of this protein is regulated by these channels, our data in dicate that SynGAP lies downstream of NMDARs and is a required intermediate for normal neural circuit function and behavior. Taken together, these data support the idea that schizophrenia may arise from abnormal signaling pathways that are mediated by NMDA receptors.

Neuropsychopharmacology (2009) 34, 1659-1672; doi:I0.1038/npp.2008.223; published online I4 January 2009
\end{abstract}

Keywords: schizophrenia; NMDA receptor; postsynaptic density; plasticity; hyperactivity; fear conditioning

\section{INTRODUCTION}

Schizophrenia is a chronic, severe, and disabling brain illness. At present, the cellular and molecular mechanisms that lead to this psychiatric condition are poorly understood. There is mounting evidence that the glutamate neurotransmitter system, and in particular NMDA receptor hypofunction, might be a contributing factor leading to symptoms of this illness (Coyle, 1996; Javitt and Zukin, 1991). NMDA receptor expression and localization is disrupted in patients with schizophrenia (Kristiansen

*Correspondence: Dr G Rumbaugh, Department of Neurobiology and Evelyn F. McKnight Brain Institute, The University of Alabama at Birmingham, 1825 University Boulevard, Birmingham, AL 35294, USA, Tel: + I 205996 64l2, Fax: + I 2059757394 ,

E-mail: grumbaugh@nrc.uab.edu

${ }^{4}$ Current address: The North Carolina State University, Raleigh, NC, USA.

Received 4 September 2008; revised 6 November 2008; accepted 25 November 2008 et al, 2007) and acutely exposing neonatal mice or rats to an NMDAR antagonist causes certain schizophrenia-like behaviors in humans (Gorter and de Bruin, 1992; Wang et al, 2004; Wangen et al, 1997). In addition, two distinct mutant mouse lines that have reduced NMDAR channel function model many of the positive, negative, and cognitive aspects of schizophrenia (Ballard et al, 2002; Mohn et al, 1999). Several mice harboring mutations in genes associated with glutamate receptor function have also demonstrated similar abnormal behaviors (Miyakawa et al, 2003; O’Tuathaigh et al, 2007; Wiedholz et al, 2008). Therefore, understanding how NMDAR function regulates neuronal circuits may provide clues to the molecular, cellular, and systems level defects that to contribute to schizophrenia.

NMDARs are glutamate-sensitive ion channels found on the postsynaptic membrane (Dingledine et al, 1999), and activation of these receptors is necessary for neural plasticity occurring both in early life and adulthood (Carmignoto and Vicini, 1992; Cline and 
Constantine-Paton, 1989). Blocking activation of these receptors during postnatal development alters input segregation in the visual and somatosensory cortex, affecting vision, and whisking behavior in rodents (Fox and Wong, 2005). NMDARs open only when bound to glutamate and the membrane is depolarized, resulting in an exquisite mechanism to detect both synaptic release of glutamate and intense neuronal activation (Mayer et al, 1984). When open, these channels are highly permeable to calcium (Mayer and Westbrook, 1987), triggering activation of kinase cascades that promote synaptic plasticity and neuronal survival during neonatal development (Fox and Wong, 2005). NMDARs are integral components of the postsynaptic density (PSD), an electron-dense structure that arises from a meshwork of proteins lying immediately under the postsynaptic membrane (Kornau et al, 1995; Sheng and Sala, 2001). NMDARs bind to several PSD-enriched scaffold and signaling molecules resulting in a vast protein complex (Kornau et al, 1995; Niethammer et al, 1996). This protein complex is believed to subserve the precise tuning of synapses in response to changing input patterns (Grant and O'Dell, 2001; Lisman and Zhabotinsky, 2001), and genetic manipulation of some of these protein in mice alters development of neocortical structures. Interestingly, of the proteins known to be associated with psychiatric disorders, there appears to be a substantial bias toward proteins that bind to NMDARs (Grant et al, 2005). Therefore, understanding the signaling pathways regulated by synaptic NMDARs may provide insight into the events that lead to experience-driven CNS development, and as a consequence, psychiatric illnesses such as schizophrenia.

Several proteins with signaling domains, such as the neuronal RasGAP SynGAP (Chen et al, 1998; Kim et al, 1998), are closely associated with NMDARs through the molecular scaffold present in the PSD. It has been hypothesized that the function of signaling proteins within the NMDAR complex is to decode synaptic information (ie, ion flux through receptors) into biochemical signals (ie, second messengers) that can be interpreted by the cellular organelles and the nucleus (Grant, 2003; Grant and O'Dell, 2001). SynGAP, which is one of the most abundant proteins in the PSD (Chen et al, 1998; Cheng et al, 2006), was originally cloned though its interactions with synaptic scaffolding proteins and is exclusively localized to excitatory synapses in the forebrain (Kim et al, 1998). Importantly, this protein associates with NMDARs through direct interactions with SAP family proteins in vivo (Chen et al, 1998; Kim et al, 1998), and is the most closely associated protein to NMDARs with a signaling domain (Grant, 2003). This suggests that SynGAP may be involved in transducing NMDAR function though the PSD. Peak SynGAP expression occurs during the height of the postnatal critical period in rodents (PND 14), but then slowly declines to adult levels by 10 weeks of age (Porter et al, 2005). SynGAP null mice die on PND 2 (Kim et al, 2003; Komiyama et al, 2002; Vazquez et al, 2004), a phenotype shared by NMDAR knockout mice (Forrest et al, 1994). Interestingly, SynGAP null mice also have enhanced cortical apoptosis (Knuesel et al, 2005), perhaps explaining their death shortly after birth. In contrast, SynGAP heterozygous mice do not die prematurely and breed normally (Kim et al, 2003; Komiyama et al, 2002; Vazquez et al, 2004). These mice, which express $50 \%$ of total SynGAP levels, have slight abnormalities in somatosensory cortex development (Barnett et al, 2006), suggesting they may have robust neurological deficits.

Because NMDAR hypofunction results in behaviors analogous to schizophrenia, and SynGAP is closely associated with a signaling complex associated with these channels, we hypothesized that SynGAP mutant mice would also display behavioral abnormalities analogous to this illness. Indeed, we report in this study that SynGAP heterozygous mutant mice display behavioral abnormalities analogous to several positive, negative, and cognitive symptoms of patients with schizophrenia. These behaviors included enhanced activity levels, reduced sensory-motor gating, altered social interactions, and reduced cognition. Some of these abnormalities were sensitive to the neuroleptic clozapine. SynGAP mutant mice demonstrated reduced sensitivity to the NMDAR antagonist MK-801, indicating that these behavioral abnormalities may be related to NMDAR hypofunction. Finally, behavioral abnormalities were present as early as 4 weeks of age, suggesting that these defects are a result of abnormal neonatal brain development. Together, our data indicate that reducing SynGAP expression may be a promising model to investigate the cell and molecular mechanisms that underlie psychiatric illnesses such as schizophrenia. On the basis of similar phenotypes shared by NMDAR and SynGAP mutant mice, our results suggest that these proteins exist in a common signaling pathway that may be dysfunctional in people with schizophrenia.

\section{MATERIALS AND METHODS}

\section{SynGAP Mutant Mice}

The generation of this SynGAP mutant line was described previously (Kim et al, 2003). The mice used for in this study were a mixed genetic background of $129 \mathrm{sv} / \mathrm{ev}$ (Taconic Farms, Inc., Hudson, NY) and c57/B6J (The Jackson Laboratory, Bar Harbor, ME). We arrived at this background by backcrossing the original F0 chimeras for six generations into C57/B6. Unfortunately, SynGAP Hets did not breed well in this nearly pure C57 background. A single backcross with a pure $129 \mathrm{sv} / \mathrm{ev}$ strain completely abolished our breeding problems. SynGAP homozygous mutant die at PND 2-5, though the SynGAP heterozygous mice used in this study appeared normal. We obtained several generations of mice (4-7 cohorts) by mating WT males with heterozygous females. The offspring from these crosses demonstrated Mendelian ratios (55\% WT/45\% Het). In addition, SynGAP heterozygous mutants appeared healthy, well groomed, and of equal size compared to WT littermates (WT male, $23.8 \pm 0.77 \mathrm{~g}$; WT females, $17.5 \pm 0.41 \mathrm{~g}$; Het males, $24.1 \pm 0.86 \mathrm{~g}$; Het females, $18.8 \pm 0.52 \mathrm{~g} ; n=20$ per group). We used similar numbers of males and females in each genotype for all tests. Some cohorts were used for more than one test, though the sequence of tests was carefully chosen (Crawley et al, 1997). For example, fear conditioning was performed after all other paradigms. Cohorts injected with drugs were not used for subsequent behavior experiments. 


\section{Open Field Analysis}

Locomotion and stereotypy were measured in an open field arena $(43.2 \times 43.2 \times 30.5 \mathrm{~cm})$ fitted with 16 evenly spaced I/R sources and sensors juxtaposed around the periphery of the four sides of the chamber (ENV-515; Med Associates, St Albans, VT). The outer walls were wrapped with white benchtop paper to limit external stimuli and light gradients. In addition, the room lights were kept low and a white noise generator was used $(55 \mathrm{~dB})$ during all runs. Each chamber was connected to a computer running software that recorded beam breaks (50 ms sampling rate). Three consecutive beam breaks represented an ambulatory episode (horizontal activity) and the total distance of all ambulatory episodes was recorded. Repeated single beam breaks within $1 \mathrm{~s}$ defined stereotypies. Therefore, horizontal activity and stereotypies could be acquired simultaneously.

\section{Acoustic Startle and Prepulse Inhibition}

Prepulse inhibition (PPI) of acoustic startle responses was measured using the Med Associates System (Med Associates). Animals were first habituated to the startle chamber and Plexiglas cylinder for $5 \mathrm{~min}$ daily for 3 days to reduce stress and unnecessary movement during the test session. On the fourth day, PPI testing was performed during the animal's dark cycle. The test began with a 5 min acclimation period where the animals were left in the chamber's cylinder undisturbed. The remainder of the test session consisted of three blocks of trials. The first block consisted of six $40 \mathrm{~ms}$, $120 \mathrm{~dB}$ sound bursts used as startle stimuli, presented with varying intertrial intervals $(8-12 \mathrm{~s})$. The second and third blocks consisted of 26 trials each, with five different trial types: startle only stimulus, no stimulus, or a $20 \mathrm{~ms}$ prepulse sound $(4 \mathrm{kHz})$ at 4,8 , or $16 \mathrm{~dB}$ above the background noise level $(65 \mathrm{~dB})$ presented $120 \mathrm{~ms}$ before the startle stimulus. The trial types were presented in pseudorandom order throughout each block with an average intertrial interval of $15 \mathrm{~s}$ (ranged from 10 to $20 \mathrm{~s}$ ). The maximum startle amplitude recorded during the $50 \mathrm{~ms}$ sampling window was used as the dependent variable. The percent PPI of the startle response was calculated as: (startle response to the startle stimuli alone-startle with the prepulse/startle to startle stimuli alone) $\times 100$. PPI data was analyzed using a mixed factor ANOVA with genotype as the between subjects factor and prepulse as the within subjects factor. When significant group interactions occurred, specific univariate comparisons were made. Significance was set as $p<0.05$.

Acoustic startle was assessed in the same apparatus by exposing test mice to six exposures of a $120 \mathrm{~dB}$ white noise stimulus and then recording the acceleration of the startle reflex. Six trials for each mouse were averaged. Before each testing session, each chamber was calibrated with standards to assure that each accelerometer produced equivalent readings.

\section{Social Interaction, Social Novelty, and Social Isolation}

The test apparatus and experimental design were based on previous studies of social interactions in mice (Crawley, 2004).
Apparatus. The test apparatus consisted of a clear plastic polycarbonate box measuring $19 \times 10.5 \times 8$ in. (R20 Cage Series; Ancare, Bellmore, NY) with two fixed polycarbonate partitions, separating the box into three chambers. The partitions have openings that allow the animal to move freely from one chamber to another; however, when limited movement was desired, clear plastic doors were be taped over the openings. A top-mounted webcam (QuckCam; Logitech, Fremont, CA) recorded the animal's movement, allowing time in each chamber to be quantified post hoc. The three-chambered apparatus was wrapped in white benchtop paper and placed on the center of a lab cart in the center of a room to minimize light gradients and shadows, temperature, sound, and other environmental conditions that could produce inherent place preferences in the test chamber.

Cylindrical chrome wire cages were used to contain stranger mice and measured $11 \mathrm{~cm}$ in height, bottom diameter $10.5 \mathrm{~cm}$, with bars spaced $1 \mathrm{~cm}$ apart (Galaxy Pencil/Utility Cup; Spectrum Diversified Designs Inc., Streetsboro, OH). A clear plastic cup filled with tap water was placed on top of these wire cages to prevent test mice from climbing on top of them. A layer of bedding (Beta Chip Hardwood Laboratory Bedding; NEPCO, Warrensburg, NY) was spread in the three-chambered apparatus during testing and was replaced after each subject to minimize scent carryover. Similarly, after each testing day, the wire cages and door inserts were wiped down with $70 \%$ ethanol and allowed to air-dry.

Sociability test. The test animal was placed in the middle chamber with the doors removed to allow it to explore the entire three-chambered apparatus for $10 \mathrm{~min}$. After the 10-min habituation period, the test animal was removed and the doors were fixed over the openings in the partitions. The animal was again paced in the middle chamber and was confined to habituate to middle chamber for $10 \mathrm{~min}$. After this 10-min center chamber habituation period, the test animal was removed and an unfamiliar adult (WT) mouse of the same sex (stranger 1) was placed inside a small wire cage in one of the side chambers. An identical empty wire cage was placed in the opposite chamber. The doors were removed and the animal was placed in the center chamber to freely explore the three chambers of the apparatus for a 10 -min test session. The thin, widely spaced bars of the wire cage allowed nose contact between the bars, but prevented the stranger mouse from initiating any social contact and limited the possibility of aggressive interactions. Thus, initiation of social contact was attributable to the interest of the test subject for the conspecific. Sociability was measured by quantifying the time spent in the chamber with stranger $1 v s$ the time spent in the chamber with the empty wire cage. Importantly, location of the stranger mouse and the empty wire cage was alternated between left and right chambers on consecutive sessions.

Social novelty and isolation. The test animal was placed in the middle chamber and allowed to explore the entire threechambered apparatus for $10 \mathrm{~min}$. During this habituation session, the small wire cages were present. After 10-min, the test animal was removed and an unfamiliar conspecific of 
the same sex (stranger 1) was placed inside one of the small wire cages whereas the other cage in the opposite side of the apparatus remained empty. The animal was placed in the center chamber to freely explore the three chambers of the apparatus for $10 \mathrm{~min}$. After this 10 -min session, the test animal was removed and a new unfamiliar mouse (stranger 2 ) was placed in the other wire cage. The test animal was again placed in the center chamber and allowed to explore the test apparatus for $10 \mathrm{~min}$. Stranger 1 and stranger 2 animals originated from different home cages and had never been in physical contact with the test mice or each other. Social recognition memory was assessed by quantifying the time the test mouse spent in each chamber during the third 10 -min session. Social isolation was assessed by measuring the time spent in the center chamber during the three 10-min sessions. WT mice spend less time in the center compartment as conspecifics are added to the apparatus, indicating their preference for social interaction over social isolation.

\section{Contextual Plus Cued Fear Conditioning}

Animals were handled for 3-5 days before training if naive. Otherwise, animals were placed in the conditioning chamber (Video Freeze; Med Associates) and allowed to explore for $3 \mathrm{~min}$, after which a $30 \mathrm{~s}$ white noise tone $(90 \mathrm{~dB})$ was presented, which coterminated with a footshock $(1 \mathrm{~s}$, $0.5 \mathrm{~mA}$ ). This tone-shock pairing was repeated twice, with an intertrial interval of $90 \mathrm{~s}$. After the third and final shock, animals remained in the training chamber for an additional $90 \mathrm{~s}$. Twenty-five hours later, animals were returned to the chamber and contextual memory was assessed by the percent of time spent freezing during a 5-min test period (no shock presentation). Four hours later, the dimensions, as well as the visual, tactile, and olfactory cues of the conditioning chamber were altered to render the context novel to the mice. Cued fear learning was then assessed. Mice were allowed to explore the new environment for $3 \mathrm{~min}$, after which the auditory cue was represented for $3 \mathrm{~min}$ and freezing behavior was measured. The time spent freezing (s) was divided by session time (context: 5 min; cued: $3 \mathrm{~min}$ ) and expressed as \% freezing. During the cued fear expression test, animals with $>40 \%$ pretone freeing were excluded from any further analysis.

\section{Working Memory Test}

Spatial working memory was assessed using a delayednonmatch-to-place task (Lee and Kesner, 2003; Li et al, 2007). The task was conducted in an automated radial arm maze (Med Associates) running custom software. SynGAP hetero and wild-type littermates were group housed. Animals were food restricted to $80-85 \%$ of body weight and maintained there for the duration of the experiment. Access to water was ad libitum. Animals were only fed reward pellets $(20 \mathrm{mg})$, a grain-based complete diet (BioServ, Frenchtown, NJ). After reaching the target weight, animals were habituated to the radial arm maze. Habituation consisted of placing the animal in the center of the maze, baiting all eight arms and opening all eight doors. Animals were then given $10 \mathrm{~min}$ to explore the maze. This process was repeated once a day until the animal could take at least six pellets in $10 \mathrm{~min}$. Forced alternation training consisted of eight trials a day with a $3.4 \mathrm{~s}$ delay. Importantly, the lights were turned off during the delay period. Animals were trained to a criterion of $75 \%$ (six of eight) correct choices for 3 consecutive days. After training, animals were tested at varying delays (four trials each delay). This was repeated for 3 consecutive days (a total of 12 trials per delay). Arm locations and delay intervals for testing were pseudorandomly chosen with the same sequence for each animal. Animals that could not achieve the training criterion were excluded from analysis (three WT, three Het). Some animals performed well below the $75 \%$ training level at all delays during testing. To test for 'forgetting' of the forced alternation rule, these animals were then given eight trials at the original $3.4 \mathrm{~s}$ training interval. If they scored below criterion during this test (less than six of eight correct), then they were excluded from the analysis (one Het and two WTs were excluded in this manner). We did not detect an interaction between day and choice performance. Therefore, data from all three test sessions were pooled for each animal.

\section{Drug Studies}

For studies with clozapine (Tocris, USA), we employed a crossover design where on a given test day, one half of the animals received vehicle and the other half received the drug. Three days later, each group received the opposite treatment. This method allowed a direct comparison of how each genotype responded to a given drug during a behavioral test. Clozapine was dissolved in a vehicle comprised ethanol, cremaphore-EL (Sigma-Aldrich, St Louis, MO), and saline (1:1:8 ratio). A single dose of MK-801 is known to induce significant NMDAR-related changes. Therefore, we did not employ a crossover design for these studies. For the MK-801 (Sigma-Aldrich) experiments, all animals from each genotype first received saline injections. A few days later, these same animals received MK-801. Therefore, these mice were only used for one trial.

\section{RESULTS}

A common phenotype of mouse models of schizophrenia is enhanced activity when subjected to a novel open field environment (Ballard et al, 2002; Miyakawa et al, 2003; Mohn et al, 1999; O'Tuathaigh et al, 2007; Wiedholz et al, 2008). Hyperactivity in the open field can be measured by assessing stereotyped behaviors, which are repetitive and purposeless movements, and this behavior is elevated in people with schizophrenia (Hill, 1974; Randrup and Munkvad, 1974). We subjected both WT and SynGAP Hets to an open field chamber and recorded stereotyped movements. SynGAP Hets demonstrated significantly elevated stereotypies relative to WT littermates (Figure 1a and b; $\left.\mathrm{F}_{(1,27)}=29.60, p<0.001\right)$. This form of elevated activity was most pronounced at the beginning of a 2 -h test session. To determine if this behavior was nonhabituating, we subjected mice to 30-min open field trials over 5 consecutive days (Figure 1c). SynGAP Hets routinely exhibited elevated stereotypic counts relative to wild-type mice, indicating that this behavior was robust and nonhabituating. Low 

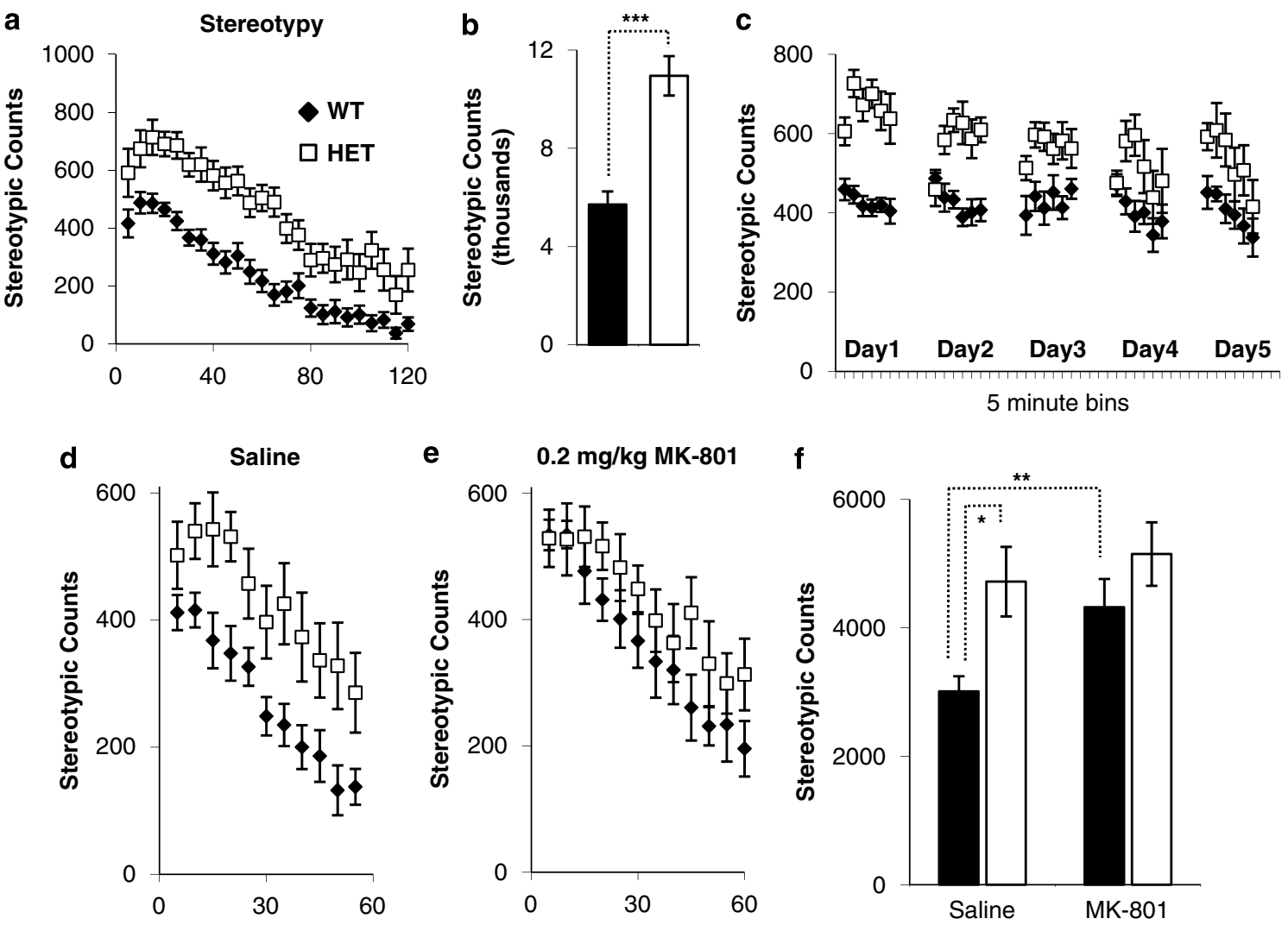

Figure I SynGAP heterozygous mutants display elevated stereotypy. (a) Three-month-old SynGAP wt $(n=14)$ and het $(n=14)$ mice were placed in the open field environment for $2 \mathrm{~h}$. Stereotypic counts were broken down by 5 -min blocks. SynGAP hets demonstrated elevated movements during each time bin. (b) Total stereotypic counts for each genotype over the entire 2-h test session; one-way ANOVA. (c) A different cohort of WT ( $n=10$ ) and Het $(n=10)$ mice were exposed to the open field environment for 30 min for 5 consecutive days. Stereotypy was broken down by 5 -min intervals. (d) This same cohort of mice was i.p. injected with $10 \mathrm{ml} / \mathrm{kg}$ of saline $30 \mathrm{~min}$ before placement into the open field. Stereotypy was measured over a 60 -min period. (e) These same mice were injected with $0.2 \mathrm{mg} / \mathrm{kg}$ MK-80 I $30 \mathrm{~min}$ before placement in the open field. ( $\mathrm{f}$ ) Comparison of total stereotypic counts from both genotypes between saline and MK-80I injections ( $n=10$ per group). A $2 \times 2$ ANOVA determined an interaction between each genotype and drug treatment group. To determine significance between individual groups, we performed a post hoc paired samples test between saline and MK-80I within genotypes, and an independent samples test between genotypes within the same drug treatment. $* p<0.05$, $* * 0<0.01$.

doses of NMDA receptor antagonists induce hyperactivity in humans and rodents, whereas mutant mice with reduced expression of NMDARs are hyperactive and do not respond to these pharmacological agents (Mohn et al, 1999). Therefore, we tested the effect of MK-801 injections on stereotyped behaviors in SynGAP mice. We detected differences between genotypes and drug treatments (genotype: $\mathrm{F}_{(1,19)}=5.44, p<0.05$; drug: $\left.\mathrm{F}_{(1,19)}=5.20, p<0.05\right)$. Saline-injected Het mice exhibited enhanced stereotypy relative to WT mice (Figure 1d and f; post hoc independent samples test; $t(-2.68), p<0.05)$. As expected, MK-801injected WT mice exhibited a robust increase in stereotypies relative to saline controls (post hoc paired samples test; $t(-3.73), p<0.01)$, whereas Het mice did not respond to these injections (Figure 1e and f; post hoc paired samples test; $t(-0.76), p=0.47)$. In addition, WT mice injected with MK-801 had similar levels of activity compared to MK-801injected Hets (post hoc independent samples test; $t(-0.59)$, $p=0.57)$. Taken together, these data indicate that NMDAR hypofunction may contribute to elevated stereotyped behaviors in SynGAP mutants.

SynGAP Hets also exhibited significantly elevated horizontal activity relative to WT littermates (Figure 2a;
$\left.\mathrm{F}_{(1,22)}=19.4, p<0.001\right)$, and this behavior was nonhabituating over repeated trials (Figure $2 \mathrm{~b}$; day $1: \mathrm{F}_{(1,18)}=29.3$, ${ }^{* * *} p<0.001$; day $2: \mathrm{F}_{(1,18)}=11.2, \quad{ }^{* *} p<0.01$; day 3: $\mathrm{F}_{(1,18)}=9.03,{ }^{* *} p<0.01$; day $4: \mathrm{F}_{(1,18)}=4.77, p<0.05$; day 5: $\left.\mathrm{F}_{(1,18)}=7.78,{ }^{*} p<0.05\right)$. A striking characteristic of SynGAP mutants was their seemingly random vectors though the open field. This behavior was in stark contrast to WT mice, which primarily ran around the outside the chamber and spent most of their time in the corners (Figure 2c). This suggested that SynGAP mice had abnormal anxiety levels in an open field. To confirm this observation, we calculated thigmotaxis (the natural propensity of mice to explore the periphery of a novel environment) for both genotypes. Interestingly, SynGAP Hets were more likely to venture into the center of the field during the first few minutes of the test session (Figure $2 \mathrm{~d} ; \mathrm{F}_{(1,20)}=3.69$, $p<0.05)$. Enhanced horizontal activity was also present in juvenile, newly weaned SynGAP mutants (Figure 2e; $\left.\mathrm{F}_{(1,15)}=8.05, p<0.05\right)$, indicating that abnormal brain development may contribute to this behavior. We next tested the effect of NMDAR blockade on locomotor activity in SynGAP mice. We detected interactions between genotypes and between drug treatments in this experiment 
a

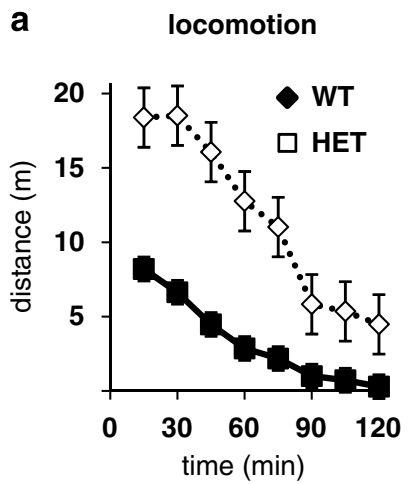

C

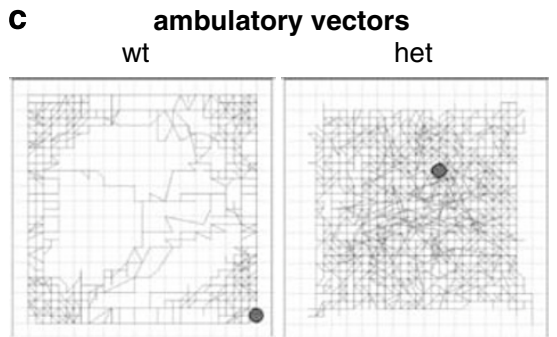
Saline

f

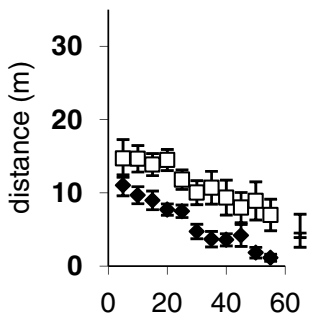

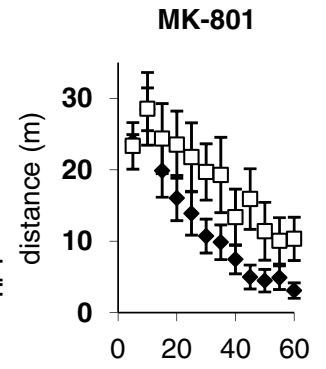
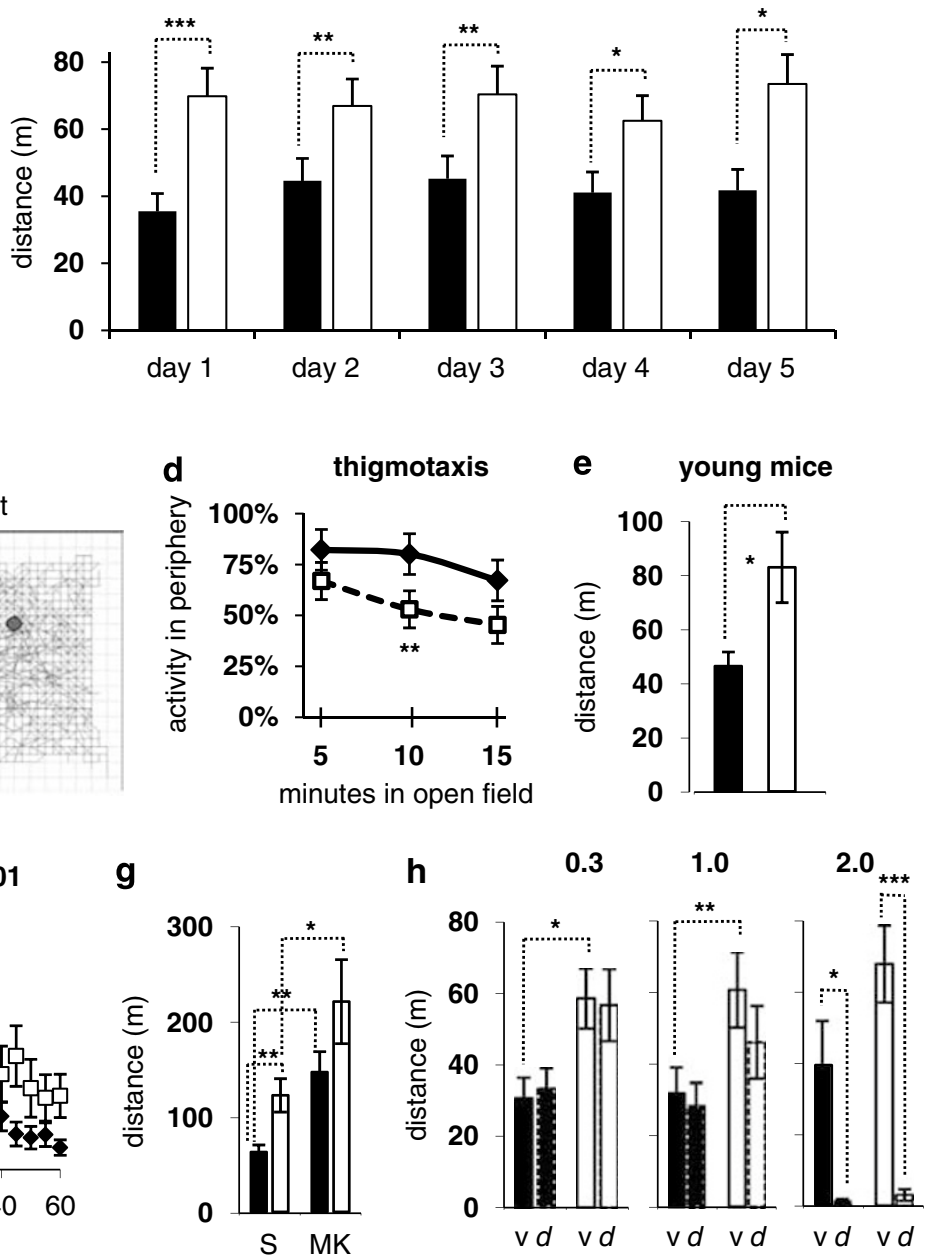

Figure 2 SynGAP Hets display enhanced horizontal locomotion. (a) Ambulatory distance of WT $(N=1$ I) and heterozygous ( $N=12)$ SynGAP mutants at 15 min intervals over a 2-h period. ANOVA. (b) WT $(n=10)$ and Het $(n=9)$ mice were exposed to the open field environment for 30 min for 5 consecutive days. Ambulatory distance was summed over a 30 -min trial period. RM ANOVA; $* p<0.05, * * 2<0.01$, **** $p<0.00$ I. (c) Representative ambulatory vector for either a WT or a Het mouse over a 30-min period. (d) Thigmotaxis calculation for each genotype $(\mathrm{WT}=10$; Het $=1 \mathrm{I}$ ). This calculation was performed for the mice in the open field shown in panel a. To determine thigmotaxis, a zonal analysis was performed over the first 15 min of the open field fun. The total distance traveled in the periphery of the chamber relative to the distance traveled in the center was calculated for each minute. Each value was averaged over a 5-min period and plotted as three blocks. We determined that an interaction between the genotypes was present by performing a repeated measures ANOVA and significance was indicated specifically at the second time point $\left(F_{(I, 20)}=10.83, p<0.01\right)$. (e) SynGAP WT $(n=9)$ and heterozygous $(n=7)$ mice between 3 and 5 weeks of age were placed in the open field and ambulatory distanced were measured. ANOVA * $p<0.05$. (f) Three to four-month-old WT $(n=10)$ and Het $(n=10)$ mice were i.p. injected with saline 30 min before placement into the open field. Ambulatory distance was measured over a 60 -min period. One week later, these same mice were injected with $0.2 \mathrm{mg} / \mathrm{kg} \mathrm{MK}-80 \mathrm{I} 30 \mathrm{~min}$ before placement in the open field. (g) Comparison of total ambulatory distance from both genotypes between saline and MK-80I injections ( $n=10$ per group). To determine significance between genotype and drug treatment, we used a $2 \times 2$ ANOVA. To determine significance between individual groups, we performed a paired samples $t$-test between saline and MK-80I within genotypes, and an independent samples $t$-test between genotypes within the same drug treatment. * $p<0.05$, *** $p<0.0 \mathrm{l}$. (h) WT $(n=9)$ and Het $(n=9)$ mice were injected with varying doses of vehicle $(\mathrm{v})$ or clozapine $(\mathrm{d} ; 0.3,1.0,2.0 \mathrm{mg} / \mathrm{kg}) 30 \mathrm{~min}$ before placement into the open field. Total horizontal distance over this period was determined for each animal. To determine significance between genotype and each drug treatment, we used a $2 \times 2$ ANOVA $\left(0.3 \mathrm{mg} / \mathrm{kg}\right.$ - genotype: $F_{(1,17)}=8.92, p<0.05 ;$ drug: $F_{(1,17)}=0.24, p=0.64 ; 1.0 \mathrm{mg} / \mathrm{kg}-$ genotype: $F_{(1,17)}=7.30, p<0.05 ;$ drug: $F_{(1,17)}=7.57, p<0.05 ; 2.0 \mathrm{mg} / \mathrm{kg}$ - genotype: $F_{(1,17)}=4.66, p=0.07$; drug: $\left.F_{(1,13)}=36.0, p<0.00 \mathrm{I}\right)$. If an interaction was observed, we performed a post hoc independent samples test to determine significance between genotypes within the same drug treatment group, and a paired samples test to determine significance within a genotype between saline and drug treatments.

(genotype: $\mathrm{F}_{(1,19)}=8.85, p<0.05 ;$ drug: $\mathrm{F}_{(1,19)}=16.8$, $p<0.01)$. MK-801 induced a significant enhancement of locomotor activity in WT and Het mice (Figure $2 \mathrm{f}$ and g; post hoc paired samples test; WT: $t(-4.33), p<0.01$; Het: $t(-2.72), p<0.05)$. Interestingly, WT mice injected with MK-801 were not different from similarly treated Hets over a 30 -min period indicating a reduced effect of this drug in
SynGAP mutants (Figure 2g; post hoc independent samples test; $t(-1.51), p=0.15)$. We next tested various doses of clozapine to determine the sensitivity of each group of mice to neuroleptic treatment. SynGAP Het mice were more active compared to WT littermates in the presence of saline (Figure $2 \mathrm{~h}$; post hoc independent samples test; $0.3 \mathrm{mg} / \mathrm{kg}=p<0.05 ; 1.0 \mathrm{mg} / \mathrm{kg}=p<0.05)$. However, this 
effect was lost in the presence clozapine indicating that SynGAP Hets are more sensitive to this drug (Figure 2h; post hoc independent samples test; $0.3 \mathrm{mg} / \mathrm{kg}, p=0.08$; $1.0 \mathrm{mg} / \mathrm{kg}, p=0.25)$. Higher doses of clozapine caused dramatic changes to horizontal activity in both genotypes (post hoc paired samples test; $\mathrm{WT}=p<0.05$; Het $=p<0.005)$. There was no significant difference in the residual locomotor activity between genotypes treated with $2 \mathrm{mg} / \mathrm{ml}$ clozapine (Figure 2h; post hoc independent samples test; $p=0.31$ ). These results demonstrate that hyperactivity caused by reduced SynGAP expression can be completely abolished by neuroleptic treatment. These data also indicate that this form of hyperactivity is not drug resistant.

We tested the hypothesis that startle reactivity and PPI were altered in SynGAP heterozygous mice. Both WT and mutants were exposed to startle stimuli in an acoustically isolated test chamber. SynGAP mutants responded more strongly to the $120 \mathrm{~dB}$ stimulus indicating abnormal processing of auditory information (Figure 3a; $\left(\mathrm{F}_{(1,21)}=5.41, p<0.05\right)$. Startle reactivity was further tested over a broad range of amplitudes. Interestingly, SynGAP Hets primarily demonstrated enhanced startle responses at the highest amplitudes (loudest pulses), suggesting that general inhibition of forebrain circuits may be disrupted (Figure 3b). SynGAP heterozygous mice also demonstrated reduced PPI (Figure $3 \mathrm{c} ; 4 \mathrm{~dB}, \mathrm{~F}_{(1,13)}=17.3, p<0.01 ; 8 \mathrm{~dB}$, $\left.\mathrm{F}_{(1,13)}=12.5, p<0.01 ; 16 \mathrm{~dB}, \mathrm{~F}_{(1,13)}=13.4, p<0.01\right)$, further indicating that forebrain circuits are dysfunctional in these mice. In contrast to open field activity, clozapine had no effect on PPI in SynGAP Hets. Clozapine $(2 \mathrm{mg} / \mathrm{kg})$ reduced the startle amplitude in both genotypes (not shown), yet had no effect on PPI in either group (Figure $3 d, p>0.05$ ). At this dose, the startle responses were reduced to the point where higher doses of clozapine were not possible.

Schizophrenia patients display reduced social interactions and are often withdrawn from society. Several mouse models of schizophrenia exhibit reduced social behavior and a tendency for social isolation (Powell and Miyakawa, 2006). Therefore, we tested various social behaviors in SynGAP mice. We first habituated both groups of mice to a three-chambered observation apparatus and recorded their preference for each end of the apparatus (Figure 4a). Neither genotype demonstrated left-right place preference during the habituation phase (WT, $Z=-1.86, p=0.06$; Het, $Z=-0.09, p=0.93)$. We next measured sociability of each genotype by assessing the preference of each mouse for an object or a novel conspecific. Both WT and heterozygous mice spent significantly more time with an unfamiliar conspecific relative to the empty wire cage (Figure $4 \mathrm{~b}$; WT, $Z=-2.37, p<0.05$; Het, $Z=-2.20, p<0.05$ ), indicating that a broad measure of sociability was normal in these mutants. To test for possible social recognition memory deficits in our mutants, we determined if they demonstrated a preference for an unfamiliar conspecific. Normal mice prefer social interactions with novel conspecifics and this choice is contingent on a memory for previous social interactions (Crawley, 2004). WT mice spent significantly more time in the novel mouse compartment (Figure 4c; $Z=-2.37, p<0.05$ ), indicating that this group of mice can form and express social memories. In contrast, SynGAP mutant mice were not able to distinguish between familiar and novel conspecifics (Figure 4c; $Z=-1.18, p=0.24$ ), indicating that there are broad and significant cognitive deficits in these mutants. To control for the possibility that

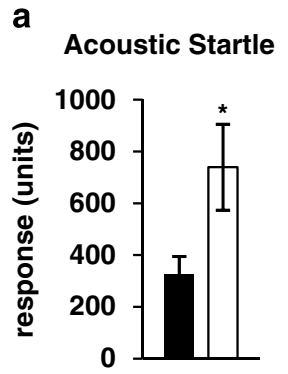

C

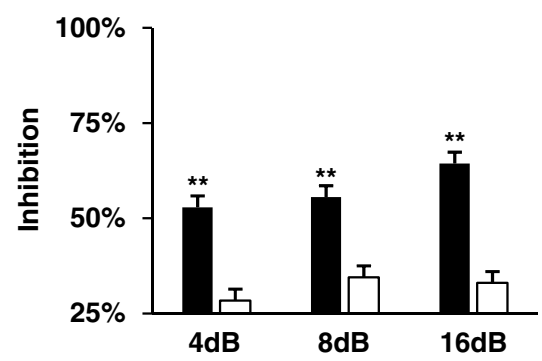

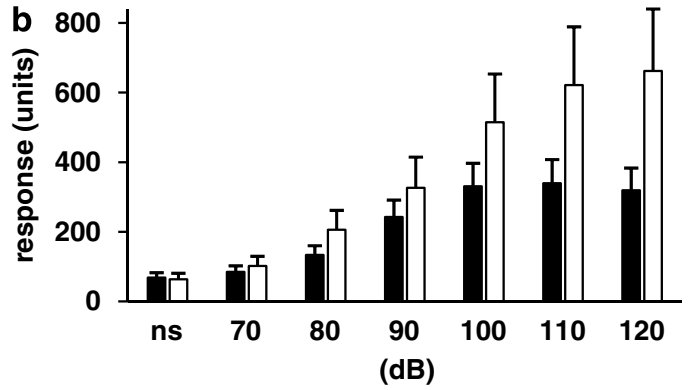

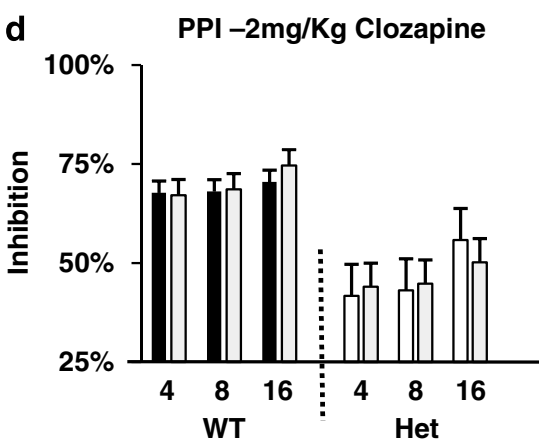

Figure 3 Reduced SynGAP expression results in enhanced startle reactivity and abnormal sensory-motor gating. (a) SynGAP WT ( $n=I I$ ) and heterozygous $(n=1 \mathrm{I})$ mutants were tested for startle responses to a $120 \mathrm{~dB}$ white noise burst. These mice were naive to the startle stimulus. ANOVA, * $p<0.05$. (b) SynGAP WT $(n=14)$ and heterozygous $(n=11)$ mutants were tested for startle responses to a series of startle responses of increasing amplitude. The startle stimuli were presented at random and each was presented at least 10 times. (c) WT $(n=8)$ and Het $(n=6)$ mice were tested for prepulse inhibition. Mixed factor ANOVA, $* * * 0.01$. (d) WT (black/gray bars, $n=8$ ) and Het (white/gray bars, $n=5$ ) mice were injected with vehicle or $2 \mathrm{mg} / \mathrm{kg}$ clozapine (gray bars) 30 min before testing in the startle chamber. There was no significant effect of clozapine on PPI in either genotype. 
SynGAP mice have reduced sensory processing, which precludes this form of learning, we tested both groups of mice for their ability to locate buried food. There was no difference in latency to locate hidden food rewards between genotypes (Figure 4d; $\mathrm{F}_{(1,11)}=0.31, p=0.59$ ), indicating that SynGAP Hets do not have a deficit in olfaction.

Mice are inherently social animals, thus making it feasible to measure their willingness to interact with conspecifics. To test for social isolation in SynGAP mutants, mice were habituated to the observation chamber and then allowed to interact with a novel conspecific. After $10 \mathrm{~min}$, a new conspecific was placed into the other end of the chamber. We then measured the time spent in the center chamber at

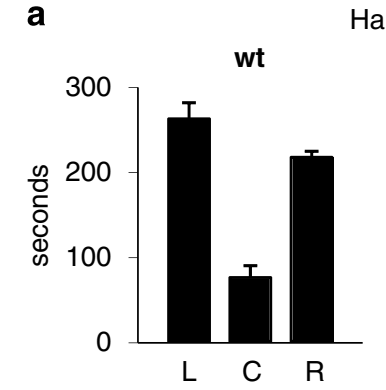

Habituation

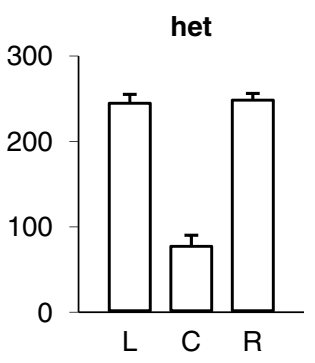

b
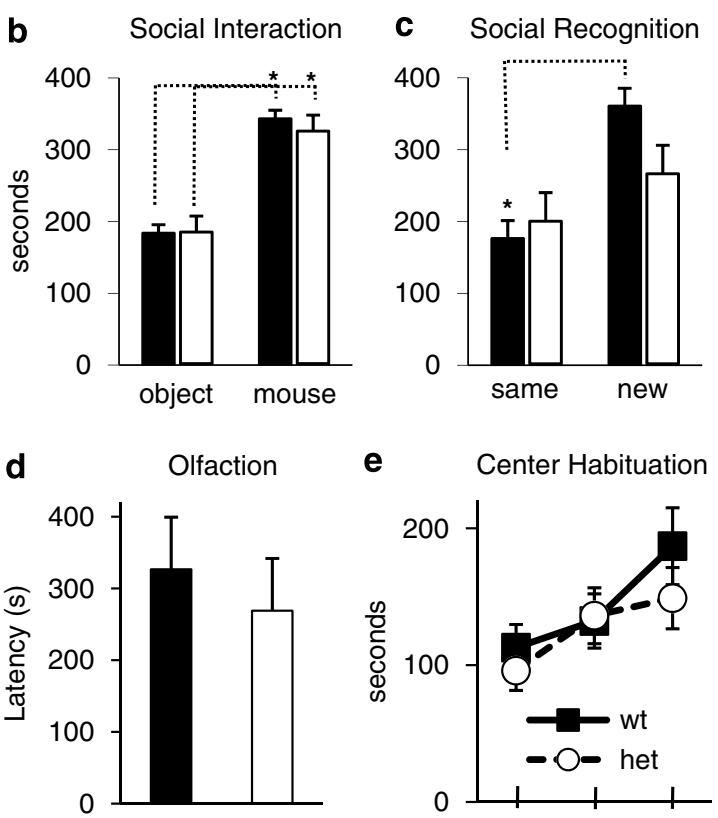

e

Center Habituation

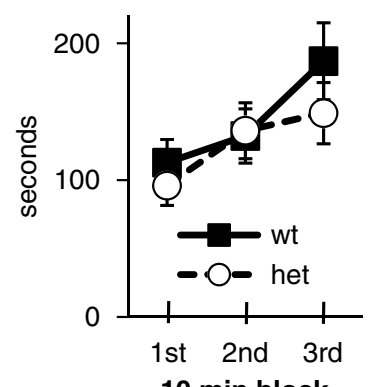

10 min block
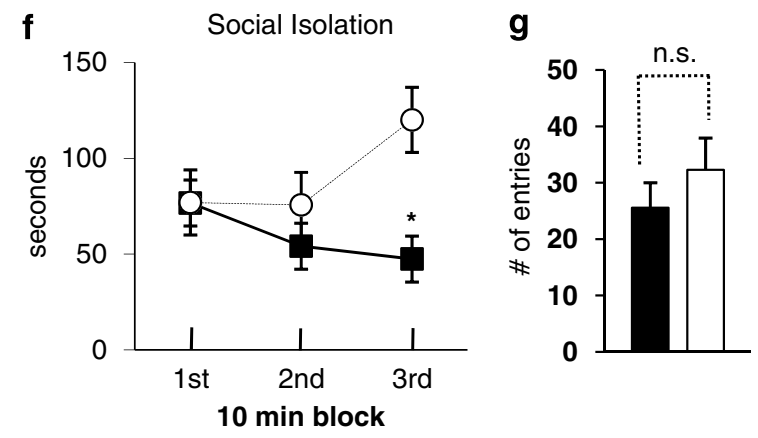

all three test phases (habituation, stranger 1 , stranger $1+2$ ). WT mice spent similar time in the center chamber over the three test sessions (Figure 4f). In contrast, SynGAP mice trended toward spending more time in the center chamber (Figure 4f). This was especially apparent in the third 10-min block, a time when there was a conspecific at each end of the chamber. SynGAP Hets spent significantly more time compared to WT littermates in the center compartment during this period (block $1, \mathrm{~F}_{(1,13)}=0.29, p=0.99$; block 2, $\mathrm{F}_{(1,13)}=1.06, p=0.32$; block $\left.3, \mathrm{~F}_{(1,13)}=8.02, p<0.05\right)$, and this difference was not because of place preference during three 10-min test sessions (Figure 4e). Importantly, SynGAP Hets did not display elevated activity compared to WT littermates during the third testing block (Figure $4 \mathrm{~g}$; $\left.\mathrm{F}_{(1,13)}=0.88, p=037\right)$. Because the center chamber represented a space that was separated from the other mice, these data indicate that SynGAP Hets prefer social isolation.

To further probe for potential cognitive defects in SynGAP Het mice, we next tested for deficits in conditioned fear. This type of associative learning is an interesting behavioral model of cognitive disruptions associated with schizophrenia, as patients with this illness demonstrate reduced autonomic responses during tests of Pavlovian fear conditioning (Astrup, 1962; Ax, 1990; Lynn, 1963). We trained both WT and heterozygous SynGAP mutant mice in a contextual plus cued fear conditioning paradigm. There was no difference in freezing behavior between WT and Het mice when reexposed to the context the next day (Figure 5a;

Figure 4 SynGAP heterozygous mutants lack short-term social memory and exhibit social isolation. (a) Both genotypes of SynGAP mice ( $N=7$ per group) were exposed to the social interaction apparatus for 10 min that contained the wire cages. There were no stranger mice present during this habituation session. Both genotypes preferred to spend time in the each end of the apparatus $(L, R)$. There was no significant left-right place preference in either genotype. Wilcoxon signed-rank test. (b) WT $(n=7)$ or Het $(n=7)$ mice were allowed to explore the social interaction apparatus for 10 min (600 s). A stranger conspecific was placed inside one of the wire cages (mouse) whereas the other end of the apparatus contained an empty, but identical, wire cage (object). The time spent in each end of the apparatus is displayed for each genotype. Both genotypes displayed a clear preference for the conspecific. Wilcoxon signed-rank test. (c) WT $(n=7)$ or Het $(n=7)$ mice were allowed to explore the social interaction apparatus for $10 \mathrm{~min}$. The test mouse was first habituated to a conspecific over 10 min (same). An unfamiliar conspecific was then added (different) and the time spend in each section of the apparatus was measured $(600 \mathrm{~s}$ total). WT mice displayed a clear preference for the novel conspecific whereas SynGAP Hets did not. Wilcoxon signed-rank test. (d) Both genotypes ( $n=6$ per group) were tested for their ability to find buried food in a test cage. Mice were first food restricted to $85 \%$ of normal body weight and then presented with a food reward that was clearly visible. The next day, these food rewards were buried in the bedding of a novel test cage and the latency to find the reward was measured. ANOVA. (e) WT and Het mice were placed into the social interaction apparatus and allowed to explore the entire environment for three consecutive I0-min sessions. The wire cages were present on each end of the apparatus during the entire test. The time spent in the center compartment was measured for each genotype ( $n=7$ per group). (f) The time in the center compartment was measured during each 10 -min session of the social recognition test (block 1 = habituation; block 2 = social interaction; block $3=$ social recognition). Differences between genotypes at each block were determined by a mixed factor ANOVA ( $n=7$ per group). $* p<0.05$. (g) Total number of chamber entries was recorded during the third block of the sociability test ( $n=7$ per group). A chamber entry was defined as a complete crossing form one compartment into the other. ANOVA. 
a

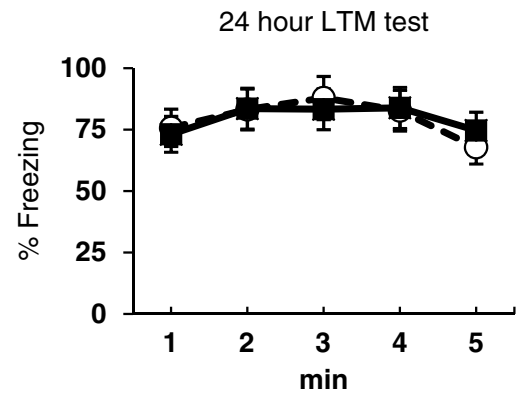

b

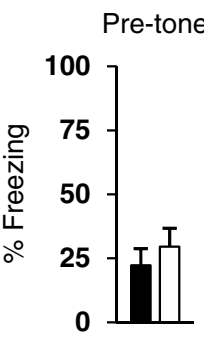

Cued Fear

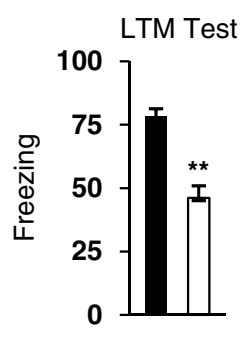

C

Cued Fear Activity levels
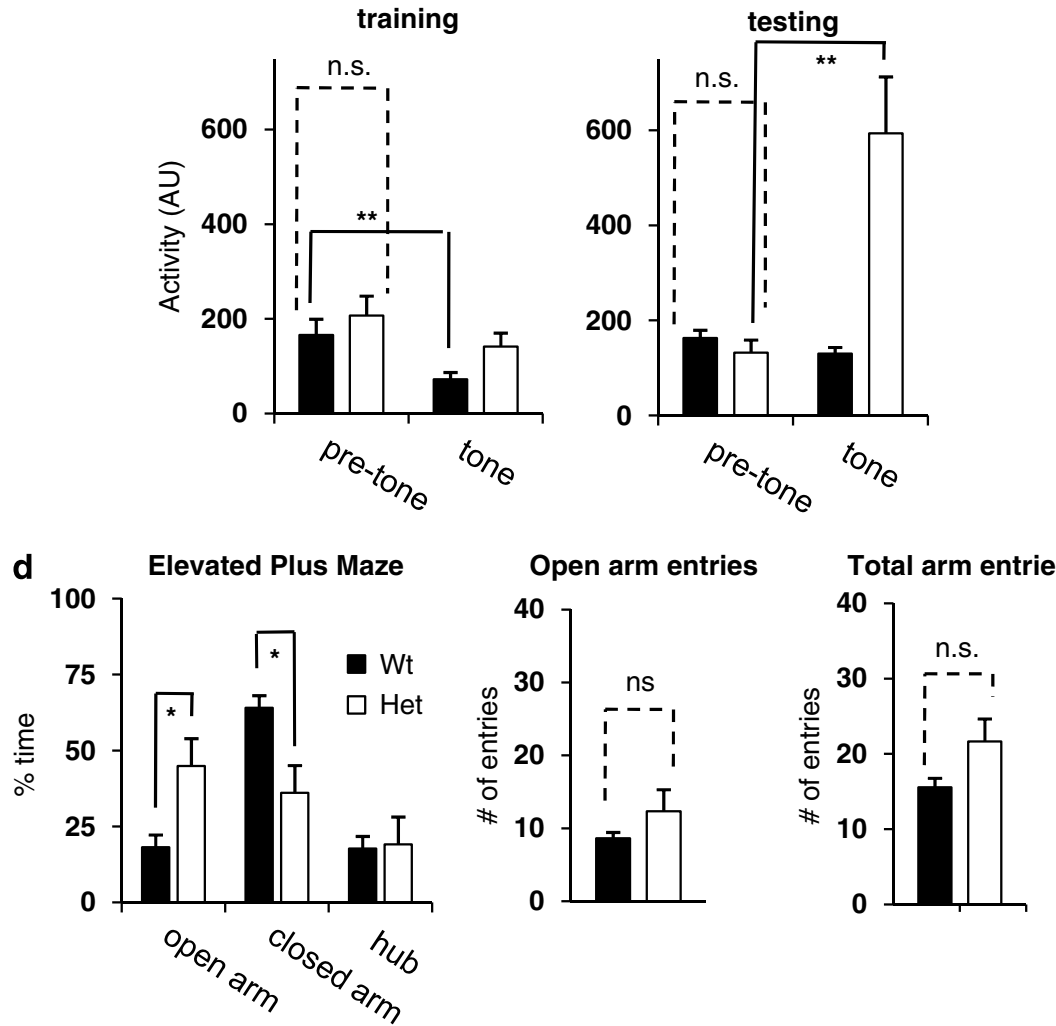

Figure 5 SynGAP mutants have abnormal behavioral responses to emotional cues. (a) SynGAP WT and Het mice were trained for contextual plus cued fear conditioning. Twenty-four hours after training, mice $(n=21 \mathrm{WT} / n=19 \mathrm{Het})$ were replaced into the testing chamber and freezing was scored over each minute of the test. ANOVA. (b) The same mice were also tested for freezing in response to an auditory cue. Left, $28 \mathrm{~h}$ after training, mice were placed into a novel context and allowed to explore for 3 min. Freezing was measured over this entire period. Right, After the 3-min acclimation period, the conditioning tone was presented for $3 \mathrm{~min}$ and freezing in response to the CS presentation was scored ( $n=17 \mathrm{WT} / n=10$ Het). ANOVA, *** $p<0.001$. (c) Left, Activity of WT $(n=17)$ and Het $(n=10)$ mice was recorded in the $30 \mathrm{~s}$ before (pretone) and immediately after (tone) the first conditioning tone. We determined an interaction only within genotypes by a $2 \times 2$ ANOVA (genotype: $F(I, 26)=28.5, p<0.001$; activity: $F(I, 26)=3.01, p=0.12 I$ ). (d) WT ( $n=8)$ and Het $(n=6)$ mice were put in the elevated T-maze for $15 \mathrm{~min}$. A computerized tracking device monitored both the time spent in each area of the maze and the number of entries in each location (ie, open arm, closed arm, and hub). Differences in arm time and arm entries were determined by an ANOVA with repeated measures.

$\left.\mathrm{F}_{(1,39)}=0.63, p=0.43\right)$. A few hours later, both groups of animals were exposed to a different experimental chamber with distinct contextual and olfactory cues. SynGAP Hets displayed significantly less freezing behavior relative to WT littermates during the presentation of the conditioning tone $\left(\mathrm{F}_{(1,26)}=9.47, p=0.005\right)$, indicating that there is a disruption in the cognitive processes associated with cued fear conditioning (Figure 5b). Because contextual freezing was normal in the mutants, these data confirm that the neural processes that permit freezing in response to conditioned fear are normal. We wondered if presentation of the auditory cue induced hyperactivity in SynGAP Hets, which perhaps could explain their reduced freezing during the expression test. During training, the first cue presentation (before any footshocks) did not induce elevated activity in either genotype. In fact, WT mice had lower activity levels during the tone presentation and Het mice trended in the same direction (Figure $5 c$; post hoc paired samples test; WT: $t(5.90), p<0.005$; Het: $t(2.18), p=0.061)$. During testing for cued fear conditioning, the initial tone presentation caused 
a similar, but nonsignificant response in WT mice. In contrast, SynGAP Hets responded to the testing tone with a dramatic elevation in activity (Figure 5c; post hoc paired samples test; $t(-4.71), p<0.005)$. Because this activity was only apparent after associative training, these data indicate that SynGAP hyperactivity is linked to the processes of cued fear. Our results strongly indicate that there are deficits in the expression of cued fear in SynGAP heterozygous mice.

A deficit in fear-mediated behaviors indicates emotional disruptions and abnormal amygdala function (LeDoux, 2000). Amygdala dysfunction is also associated with abnormal anxiety, and a clinically relevant relationship between anxiety and schizophrenia may exist in certain patients (Braga et al, 2004). Therefore, we exposed WT and Het mice to the elevated plus maze, an accepted measure of generalized anxiety in rodents (Crawley et al, 1997). Het mice spent less time in the closed arm $\left(\mathrm{F}_{(1,13)}=6.81\right.$, $p<0.05)$ and more time in the open arm $\left(\mathrm{F}_{(1,13)}=9.16\right.$, $p<0.05)$ of the maze relative to WT mice, indicating that SynGAP mutants have abnormal anxiety levels (Figure 5d). Importantly, there were no differences between genotypes in open $\left(\mathrm{F}_{(1,13)}=1.87, p=0.20\right)$ or total $\left(\mathrm{F}_{(1,13)}=1.04\right.$, $p=0.33$ ) arm entries (Figure $5 \mathrm{~d}$ ), indicating that Het mice were not more active in the maze run. Together, these data strongly indicate that SynGAP mutant mice do not properly perceive danger, and this phenotype is not related to generalized or novelty-induced hyperactivity.

Defects in working memory are a hallmark of schizophrenia and there are no effective treatments for this aspect of the illness. Rodent models of schizophrenia demonstrate time-dependent working memory deficits (Li et al, 2007). Therefore, we tested the idea that SynGAP Hets would also have this type of working memory impairment. SynGAP WT and Hets were first habituated to an automated eightarm radial maze and then subjected to multiple days of forced alternation. These animals were then tested for the ability to nonmatch-to-place at different delay intervals. Both groups of mice were able to learn the forced alteration rule and there was no difference between genotypes in total errors during training (Figure 6a). During testing, the nonmatching ability of WT mice was not affected by time $(p>0.05)$, and performance at both 5 and $30 \mathrm{~s}$ met the training criteria (one-sample $t$-test, $p>0.05$ ). In contrast, Het mice demonstrated a dramatic time-dependent decrease in nonmatching performance (Figure $6 \mathrm{~b} ; \mathrm{F}_{(1,13)}=23.6$, $p<0.005)$ ). In fact, Het performance was significantly below the training criterion level at $30 \mathrm{~s}$ (one-sample $t$-test; $p<0.005)$ and was not different from random chance (one-sample $t$-test; $p=0.28$ ). Importantly, decision latency and test session duration were not different between the two groups (Figure $6 c ; p>0.05$ ). Together, these data indicate that SynGAP Hets have significant spatial working memory deficits.

\section{DISCUSSION}

In this study, we report that SynGAP mutant mice have behavioral abnormalities similar to other mouse models of schizophrenia (Ballard et al, 2002; Miyakawa et al, 2003; Mohn et al, 1999; O'Tuathaigh et al, 2007; Wiedholz et al, 2008). SynGAP heterozygous mice display behaviors that a Habituation
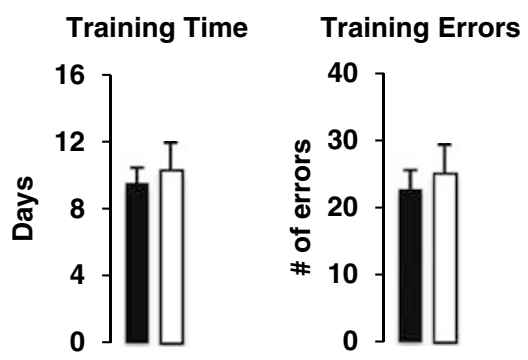

b

Working Memory Performance

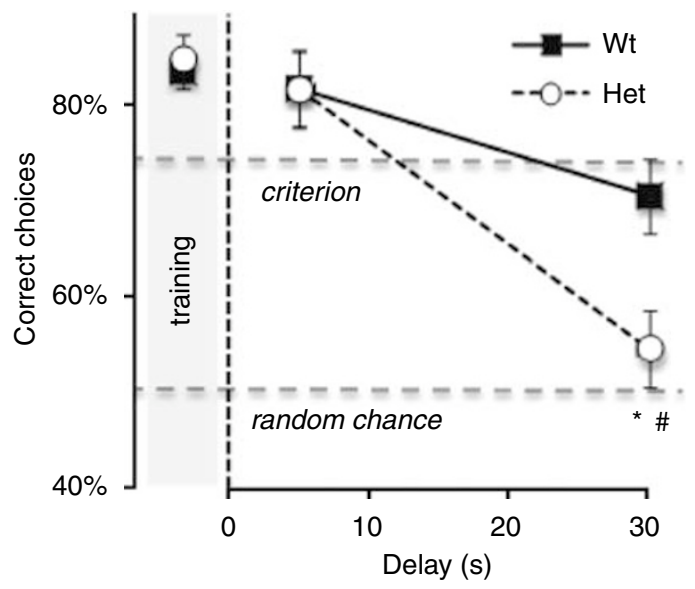

C Choice Latency

Test Session Duration
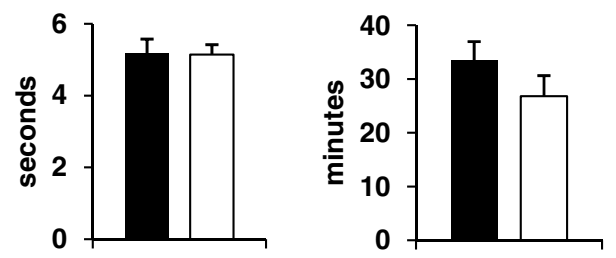

Figure 6 SynGAP mutants have working memory deficits. (a) Data describes the performance of each genotype during the habituation (number of days until animal took six pellets in $10 \mathrm{~min}$ ) and training portion of the task (see Materials and Methods section). (b) SynGAP WT $(n=8)$ and Het $(n=7)$ mice were tested nonmatch-to-place performance at 5and 30-s delays. The gray bar represents the performance of each group during the training sessions ( $3.4 \mathrm{~s}$ delay). *ANOVA with repeated measures, $p<0.005$; \# one-sample t-test, $p<0.005$. One-sample $t$-test values were $75 \%(0.75)$ for training criterion and 50\% (0.50) for random chance. (c) Left, Average choice latency indicates time taken to enter the arm during nonmatching. This value includes the $2.4 \mathrm{~s}$ it takes for the door to fully open in our maze. Right, Average test session duration for each animal (average over 3 days).

are related to the positive, negative, and cognitive symptoms that characterize this illness (Powell and Miyakawa, 2006). These results were somewhat surprising, as SynGAP mutant mice have been tested previously for behavioral abnormalities. Although a mild spatial learning deficit has been reported in these mice, there was no report of any other behavioral abnormalities (Komiyama et al, 2002). SynGAP mutants behave normally in the homecage environment (GR unpublished observation), breed and groom normally, are of equivalent size compared to WT mice, and have similar life expectancies (GR unpublished data). These data indicate that the robust neurological and behavioral deficits inherent to reduced SynGAP expression 
are only detectable by very specific behavioral assays and detailed observation. It has been hypothesized that core PSD proteins, such as SynGAP, are required for proper synaptic function, and as a result, may underlie certain psychiatric illnesses (Grant et al, 2005). In support of this idea, various PSD proteins, including PSD-95, are disrupted in the brains of schizophrenia patients (Kristiansen et al, 2006). However, even though PSD-95 mutants exhibit robust learning deficits (Migaud et al, 1998), they do not display the characteristic behaviors of mouse models of schizophrenia (Yao et al, 2004). Therefore, we propose that SynGAP serves a unique regulatory role in the PSD, and may be required for proper NMDAR function in vivo.

NMDAR antagonists induce psychosis in humans, whereas similar treatments in mice cause behavioral abnormities including profound hyperactivity (Javitt and Zukin, 1991). SynGAP binds to NMDARs at excitatory synapses (Kim et $a l, 1998$ ) and the activity of this protein is regulated by calcium influx through these channels (Oh et al, 2004). Therefore, we hypothesized that the hyperactivity exhibited by SynGAP mice might be caused, at least in part, by reduced function of NMDARs. This idea was supported by the reduced effect of MK-801 on hyperactivity in SynGAP mutants. In fact, the effect of NMDAR antagonists on stereotypy was occluded in SynGAP mutants, whereas MK-801-injected WT mice had enhanced levels of activity, which was not significantly different from saline-injected Hets. Previous studies have demonstrated that SynGAP is an intracellular effector of NMDAR channel activity (Kim et al, 2005; Oh et al, 2004). Therefore, whereas channel function measured electrophysiologically may indicate that a receptor is functioning normally, critical kinase cascades downstream of activated NMDARs may be dysregulated in SynGAP mutants. Therefore, reduced SynGAP expression could lead to NMDAR hypofunction that is ion channel-independent. Indeed, we have previously shown that reducing SynGAP expression alters MAP kinase signaling in forebrain neurons (Rumbaugh et al, 2006). Although these data suggest the intriguing possibility that NMDAR hypofunction in SynGAP mutants contributes to hyperactivity, it is also possible that some other mechanism contributes to this phenotype in SynGAP mutants. Indeed, locomotion and stereotypy are regulated by numerous neural mechanisms that are independent of NMDAR function (Albin et al, 1989). Therefore, more sophisticated experiments will be necessary to determine the cell and molecular mechanisms that are regulated by SynGAP, which contribute to hyperactivity in mice.

In addition to hyperactivity, SynGAP mice display altered sensory-motor gating and reduced social interactions. SynGAP mutants demonstrated enhanced startle reactivity and reduced PPI, which indicates that these mutants have robust deficits in forebrain circuit function (Geyer et al, 2001; Koch, 1999). It is unlikely that enhanced startle reactivity results in altered PPI in these mice, as there are numerous instances where one measure is altered whereas the other is intact (Geyer et al, 2001). Rather, distinct neural processes are likely altered in SynGAP mutants that disrupt the processing of auditory information and regulate sensory-motor gating. SynGAP heterozygous mice also lack the ability to discriminate conspecifics in a social setting. Conspecific discrimination is essential for an organized social hierarchy to develop in a group of animals (Crawley, 2004). This indicates that reduced SynGAP function results in a significant cognitive defect in mice that may alter social interactions. In support of this idea, when given a choice to interact with conspecifics or to remain isolated, SynGAP mutants spent more time isolated compared to WT siblings. It is unclear if social isolation is related to deficits in social memory, though we speculate that isolation and social memory deficits in our mutants arise from distinct neural mechanisms.

Reduced SynGAP expression causes abnormal expression of conditioned fear. The cell and molecular mechanisms that promote fear conditioning are believed to underlie emotional learning in animals (LeDoux, 2000). One hallmark of schizophrenia is development of a flat affect and persistent negative emotions (American Psychiatric Association and American Psychiatric Association. Task Force on DSM-IV, 1994), and many people with schizophrenia are unable to convey empathy further suggesting that emotional regulation is disrupted in these patients (Taylor et al, 2005). SynGAP mutants exhibited reduced freezing in response to a conditioning tone previously associated with a mild footshock. The freezing response in these mice appears intact, as behavioral responses to a fear-associated context were normal. These data indicate that fear elicited by an auditory stimulus is selectively altered in SynGAP mutants. Both contextual and cued fear conditioning require the lateral amygdala (Phillips and Ledoux, 1992). Therefore, it is unlikely that freezing defects during the test of cued fear are a consequence of abnormal learning and memory. It is possible that auditory stimulation disrupts the freezing response of Het mice during the cued test. There was no difference between WT and Het mice activity during the conditioning tone presentation, though activity was dramatically elevated in Het mice during tone presentation in the retrieval test. We speculate that reduced freezing during the CS presentation in Het mice results from alterations in tone processing that is uncovered by associative learning. These data, together with our observation of a clear anxiety phenotype in these mice, suggests that reduced SynGAP expression causes defects to emotional circuits that result in diminished responses to environmental cues that elicit fear.

Several recent reports have demonstrated that mutant mice with altered glutamate neurotransmitter function exhibit behaviors that are analogous to schizophrenia (Ballard et al, 2002; Miyakawa et al, 2003; Mohn et al, 1999; O'Tuathaigh et al, 2007; Wiedholz et al, 2008). Interestingly, the behavioral abnormalities demonstrated by SynGAP mutant mice are most closely associated with the phenotypes reported for mutant mice with either low expression or reduced function of NMDARs (Ballard et al, 2002; Mohn et al, 1999). In fact, the behavioral abnormalities of SynGAP mutants are nearly identical to these previously described mouse models of schizophrenia. For instance, all three of these mutant lines respond poorly to low doses of NMDAR antagonists, exhibit robust hyperactivity, suffer from reduced cognition and have altered sensory-motor gating. These data suggest that NMDARs and SynGAP exist in a common biochemical pathway that is necessary for normal brain function and behavior.

Is there a link between NMDAR activity and SynGAP function that might explain the strikingly similar behavioral 
abnormities shared by these mutant mouse lines? We hypothesize that NMDARs signal through SynGAP to regulate the trafficking of AMPARs in vivo, and this pathway may become dysfunctional in patients with schizophrenia. NMDAR function is necessary for many critical cellular processes including the activation of biochemical cascades that support neocortical development, synaptic plasticity and memory formation (Citri and Malenka, 2008). Over the past decade, evidence has emerged that trafficking of GluR1-containing AMPARs is critical for the induction of certain forms of synaptic plasticity (Malinow and Malenka, 2002). This form of regulated AMPAR trafficking is dependent upon NMDAR activity, and enhanced synaptic efficacy contributes to learning and memory in brain regions such as the hippocampus and amygdala (Pastalkova et al, 2006; Rogan et al, 1997; Rumpel et al, 2005; Whitlock et al, 2006). Importantly, trafficking of GluR1-containing AMPARs has been demonstrated during various forms of emotional, contextual and reward learning (Conrad et al, 2008; Hu et al, 2007; Matsuo et al, 2008; Rumpel et al, 2005; Yeh et al, 2006). In addition, AMPAR trafficking is also associated with plasticity of synaptic inputs in the somatosensory cortex during altered visual experience (Goel et al, 2006). Therefore, abnormal AMPAR trafficking could explain many of the behavioral impairments described by certain mouse models of schizophrenia and may underlie certain symptoms of this illness. In support of this idea, GluR1 (GRIA1) has recently been identified as a schizophrenia susceptibility gene (Magri et al, 2006), and mRNA and protein expression of this AMPAR subunit is altered in patients diagnosed with schizophrenia (Beneyto et al, 2007). Recently, mice lacking the GRIA1 gene were reported to display abnormal behaviors similar to that of SynGAP and NMDAR mutants (Wiedholz et al, 2008). NMDARs also regulate SynGAP function in vivo by activation of CamKII activity (Oh et al, 2004), and mice with reduced CAMKII expression have shared endophenotype commonalities with SynGAP Hets (Yamasaki et al, 2008). CAMKII phosphorylation is a trigger for GluR1 insertion during certain forms of synaptic plasticity (Zhu et al, 2002). Previously, we have shown that SynGAP is a potent regulator of AMPARS that contain GluR1 (Rumbaugh et al, 2006), and regulation of SynGAP expression alters spine morphogenesis and synaptic strength (Vazquez et al, 2004). At synapses, SynGAP binds to NMDARs and regulates signal transduction pathways that control AMPAR trafficking (Kim et al, 2005; Rumbaugh et al, 2006). Therefore, we propose that a NMDAR-CAMKIISynGAP-GluR1 pathway is engaged in certain forebrain circuits that govern activity, sociability, and cognition. When this pathway is compromised, the refinement of cortical circuits may be disrupted during the neonatal critical period. Alternatively, altered signaling through this pathway may cause changes in neuronal integration from adult circuits that lead to abnormal behaviors. Future studies will be necessary to determine the role of SynGAP in development $v s$ the function of this protein in mature neuronal circuits.

In conclusion, we present evidence that abnormal intracellular signaling associated with NMDAR activity results in broad neurological deficits in mice. The abnormal behaviors demonstrated by SynGAP mutants are in agree- ment with recently published mouse models of schizophrenia. Therefore, understanding the role of NMDARSynGAP signaling in neurons may provide insight into the neural mechanisms underlying mental illnesses.

\section{ACKNOWLEDGEMENTS}

We thank Dr James Meador-Woodruff for his advice and critical evaluation of this study. We also thank Dr Richard L Huganir for sharing the SynGAP mutant mouse line. This work was generously supported by The Evelyn F McKnight Brain Institute, The University of Alabama at Birmingham and the Alabama Health Services Foundation (GR).

\section{DISCLOSURE/CONFLICT OF INTEREST}

The authors declare that, except for income received from my primary employer, no financial support or compensation has been received from any individual or corporate entity over the past 3 years for research or professional service and there are no personal financial holdings that could be perceived as constituting a potential conflict of interest.

\section{REFERENCES}

Albin RL, Young AB, Penney JB (1989). The functional anatomy of basal ganglia disorders. Trends Neurosci 12: 366-375.

American Psychiatric Association, American Psychiatric Association. Task Force on DSM-IV (1994). Diagnostic and Statistical Manual of Mental Disorders: DSM-IV, 4th edn. American Psychiatric Association: Washington, DC, xxvii, $886 \mathrm{pp}$.

Astrup C (1962). Schizophrenia; Conditional Reflex Studies. Thomas: Springfield, IL, xx, 345pp.

Ax AF (1990). Individual differences in autonomic learning: a quarter century of reflection. Int J Psychophysiol 10: 1-9.

Ballard TM, Pauly-Evers M, Higgins GA, Ouagazzal AM, Mutel V, Borroni E et al (2002). Severe impairment of NMDA receptor function in mice carrying targeted point mutations in the glycine binding site results in drug-resistant nonhabituating hyperactivity. J Neurosci 22: 6713-6723.

Barnett MW, Watson RF, Vitalis T, Porter K, Komiyama NH, Stoney PN et al (2006). Synaptic Ras GTPase activating protein regulates pattern formation in the trigeminal system of mice. J Neurosci 26: 1355-1365.

Beneyto M, Kristiansen LV, Oni-Orisan A, McCullumsmith RE, Meador-Woodruff JH (2007). Abnormal glutamate receptor expression in the medial temporal lobe in schizophrenia and mood disorders. Neuropsychopharmacology 32: 1888-1902.

Braga RJ, Petrides G, Figueira I (2004). Anxiety disorders in schizophrenia. Compr Psychiatry 45: 460-468.

Carmignoto G, Vicini S (1992). Activity-dependent decrease in NMDA receptor responses during development of the visual cortex. Science 258: 1007-1011.

Chen HJ, Rojas-Soto M, Oguni A, Kennedy MB (1998). A synaptic Ras-GTPase activating protein (p135 SynGAP) inhibited by CaM kinase II. Neuron 20: 895-904.

Cheng DM, Hoogenraad CC, Rush J, Ramm E, Schlager MA, Duong $\mathrm{DM}$ et al (2006). Relative and absolute quantification of postsynaptic density proteome isolated from rat forebrain and cerebellum. Mol Cell Proteomics 5: 1158-1170.

Citri A, Malenka RC (2008). Synaptic plasticity: multiple forms, functions, and mechanisms. Neuropsychopharmacology 33: $18-41$. 
Cline HT, Constantine-Paton M (1989). NMDA receptor antagonists disrupt the retinotectal topographic map. Neuron 3: 413-426.

Conrad KL, Tseng KY, Uejima JL, Reimers JM, Heng LJ, Shaham Y et al (2008). Formation of accumbens GluR2-lacking AMPA receptors mediates incubation of cocaine craving. Nature 454: $118-121$.

Coyle JT (1996). The glutamatergic dysfunction hypothesis for schizophrenia. Harv Rev Psychiatry 3: 241-253.

Crawley JN (2004). Designing mouse behavioral tasks relevant to autistic-like behaviors. Ment Retard Dev Disabil Res Rev 10: 248-258.

Crawley JN, Belknap JK, Collins A, Crabbe JC, Frankel W, Henderson $\mathrm{N}$ et al (1997). Behavioral phenotypes of inbred mouse strains: implications and recommendations for molecular studies. Psychopharmacology 132: 107-124.

Dingledine R, Borges K, Bowie D, Traynelis SF (1999). The glutamate receptor ion channels. Pharmacol Rev 51: 7-61.

Forrest D, Yuzaki M, Soares HD, Ng L, Luk DC, Sheng M et al (1994). Targeted disruption of NMDA receptor 1 gene abolishes NMDA response and results in neonatal death. Neuron 13: 325-338.

Fox K, Wong RO (2005). A comparison of experience-dependent plasticity in the visual and somatosensory systems. Neuron 48: 465-477.

Geyer MA, Krebs-Thomson K, Braff DL, Swerdlow NR (2001). Pharmacological studies of prepulse inhibition models of sensorimotor gating deficits in schizophrenia: a decade in review. Psychopharmacology 156: 117-154.

Goel A, Jiang B, Xu LW, Song L, Kirkwood A, Lee HK (2006). Cross-modal regulation of synaptic AMPA receptors in primary sensory cortices by visual experience. Nat Neurosci 9: 1001-1003.

Gorter JA, de Bruin JP (1992). Chronic neonatal MK-801 treatment results in an impairment of spatial learning in the adult rat. Brain Res 580: 12-17.

Grant SGN (2003). Synapse signalling complexes and networks: machines underlying cognition. Bioessays 25: 1229-1235.

Grant SGN, Marshall MC, Page KL, Cumiskey MA, Armstrong JD (2005). Synapse proteomics of multiprotein complexes: en route from genes to nervous system diseases. Hum Mol Genet 14: R225-R234.

Grant SGN, O’Dell TJ (2001). Multiprotein complex signaling and the plasticity problem. Curr Opin Neurobiol 11: 363-368.

Hill D (1974). Non-verbal behaviour in mental illness. $\mathrm{Br} J$ Psychiatry 124: 221-230.

Hu HL, Real E, Takamiya K, Kang MG, Ledoux J, Huganir RL et al (2007). Emotion enhances learning via norepinephrine regulation of AMPA-receptor trafficking. Cell 131: 160-173.

Javitt DC, Zukin SR (1991). Recent advances in the phencyclidine model of schizophrenia. Am J Psychiatry 148: 1301-1308.

Kim JH, Lee HK, Takamiya K, Huganir RL (2003). The role of synaptic GTPase-activating protein in neuronal development and synaptic plasticity. J Neurosci 23: 1119-1124.

Kim JH, Liao DZ, Lau LF, Huganir RL (1998). SynGAP: a synaptic RasGAP that associates with the PSD-95/SAP90 protein family. Neuron 20: 683-691.

Kim MJ, Dunah AW, Wang YT, Sheng M (2005). Differential roles of NR2A- and NR2B-containing NMDA receptors in and AMPA receptor Ras-ERK signaling trafficking. Neuron 46: 745-760.

Knuesel I, Elliott A, Chen HJ, Mansuy IM, Kennedy MB (2005). A role for synGAP in regulating neuronal apoptosis. Eur J Neurosci 21: 611-621.

Koch M (1999). The neurobiology of startle. Prog Neurobiol 59: 107-128.

Komiyama NH, Watabe AM, Carlisle HJ, Porter K, Charlesworth P, Monti J et al (2002). SynGAP regulates ERK/MAPK signaling, synaptic plasticity, and learning in the complex with postsynaptic density 95 and NMDA receptor. J Neurosci 22: 9721-9732.
Kornau HC, Schenker LT, Kennedy MB, Seeburg PH (1995). Domain interaction between NMDA receptor subunits and the postsynaptic density protein PSD-95. Science 269: 1737-1740.

Kristiansen LV, Beneyto M, Haroutunian V, Meador-Woodruff JH (2006). Changes in NMDA receptor subunits and interacting PSD proteins in dorsolateral prefrontal and anterior cingulate cortex indicate abnormal regional expression in schizophrenia. Mol Psychiatry 11: 737-747, 705.

Kristiansen LV, Huerta I, Beneyto M, Meador-Woodruff JH (2007). NMDA receptors and schizophrenia. Curr Opin Pharmacol 7: $48-55$.

LeDoux JE (2000). Emotion circuits in the brain. Annu Rev Neurosci 23: 155-184.

Lee I, Kesner RP (2003). Time-dependent relationship between the dorsal hippocampus and the prefrontal cortex in spatial memory. J Neurosci 23: 1517-1523.

Li W, Zhou Y, Jentsch JD, Brown RA, Tian X, Ehninger D et al (2007). Specific developmental disruption of disrupted-inschizophrenia-1 function results in schizophrenia-related phenotypes in mice. Proc Natl Acad Sci USA 104: 18280-18285.

Lisman JE, Zhabotinsky AM (2001). A model of synaptic memory: a CaMKII/PP1 switch that potentiates transmission by organizing an AMPA receptor anchoring assembly. Neuron 31: 191-201.

Lynn R (1963). Russian theory and research on schizophrenia. Psychol Bull 60: 486-498.

Magri C, Gardella R, Barlati SD, Podavini D, Iatropoulos P, Bonomi $S$ et al (2006). Glutamate AMPA receptor subunit 1 gene (GRIA1) and DSM-IV-TR schizophrenia: a pilot case-control association study in an Italian sample. Am J Med Genet B Neuropsychiatr Genet 141B: 287-293.

Malinow R, Malenka RC (2002). AMPA receptor trafficking and synaptic plasticity. Annu Rev Neurosci 25: 103-126.

Matsuo N, Reijmers L, Mayford M (2008). Spine-type-specific recruitment of newly synthesized AMPA receptors with learning. Science 319: 1104-1107.

Mayer ML, Westbrook GL (1987). Permeation and block of $N$-methyl-D-aspartic acid receptor channels by divalent cations in mouse cultured central neurones. J Physiol 394: 501-527.

Mayer ML, Westbrook GL, Guthrie PB (1984). Voltage-dependent block by $\mathrm{Mg}^{2+}$ of NMDA responses in spinal cord neurones. Nature 309: 261-263.

Migaud M, Charlesworth P, Dempster M, Webster LC, Watabe AM, Makhinson $\mathrm{M}$ et al (1998). Enhanced long-term potentiation and impaired learning in mice with mutant postsynaptic density-95 protein. Nature 396: 433-439.

Miyakawa T, Leiter LM, Gerber DJ, Gainetdinov RR, Sotnikova TD, Zeng $\mathrm{H}$ et al (2003). Conditional calcineurin knockout mice exhibit multiple abnormal behaviors related to schizophrenia. Proc Natl Acad Sci USA 100: 8987-8992.

Mohn AR, Gainetdinov RR, Caron MG, Koller BH (1999). Mice with reduced NMDA receptor expression display behaviors related to schizophrenia. Cell 98: 427-436.

Niethammer M, Kim E, Sheng M (1996). Interaction between the C terminus of NMDA receptor subunits and multiple members of the PSD-95 family of membrane-associated guanylate kinases. J Neurosci 16: 2157-2163.

O’Tuathaigh CM, Babovic D, O'Sullivan GJ, Clifford JJ, Tighe O, Croke DT et al (2007). Phenotypic characterization of spatial cognition and social behavior in mice with 'knockout' of the schizophrenia risk gene neuregulin 1. Neuroscience 147: $18-27$.

Oh JS, Manzerra P, Kennedy MB (2004). Regulation of the neuronspecific ras GTPase-activating protein, synGAP, by $\mathrm{Ca}^{2+}$ / calmodulin-dependent protein kinase II. J Biol Chem 279: 17980-17988.

Pastalkova E, Serrano P, Pinkhasova D, Wallace E, Fenton AA, Sacktor TC (2006). Storage of spatial information by the maintenance mechanism of LTP. Science 313: 1141-1144. 
Phillips RG, Ledoux JE (1992). Differential contribution of amygdala and hippocampus to cued and contextual fear conditioning. Behav Neurosci 106: 274-285.

Porter K, Komiyama NH, Vitalis T, Kind PC, Grant SGN (2005). Differential expression of two NMDA receptor interacting proteins, PSD-95 and SynGAP during mouse development. Eur J Neurosci 21: 351-362.

Powell CM, Miyakawa T (2006). Schizophrenia-relevant behavioral testing in rodent models: a uniquely human disorder? Biol Psychiatry 59: 1198-1207.

Randrup A, Munkvad I (1974). Pharmacology and physiology of stereotyped behavior. J Psychiatr Res 11: 1-10.

Rogan MT, Staubli UV, LeDoux JE (1997). Fear conditioning induces associative long-term potentiation in the amygdala. Nature 390: 604-607.

Rumbaugh G, Adams JP, Kim JH, Huganir RL (2006). SynGAP regulates synaptic strength and mitogen-activated protein kinases in cultured neurons. Proc Natl Acad Sci USA 103: 4344-4351.

Rumpel S, LeDoux J, Zador A, Malinow R (2005). Postsynaptic receptor trafficking underlying a form of associative learning. Science 308: 83-88.

Sheng M, Sala C (2001). PDZ domains and the organization of supramolecular complexes. Annu Rev Neurosci 24: 1-29.

Taylor SF, Phan KL, Britton JC, Liberzon I (2005). Neural response to emotional salience in schizophrenia. Neuropsychopharmacology 30: 984-995.

Vazquez LE, Chen HJ, Sokolova I, Knuesel I, Kennedy MB (2004). SynGAP regulates spine formation. J Neurosci 24: 8862-8872.
Wang C, Anastasio N, Popov V, Leday A, Johnson KM (2004). Blockade of $N$-methyl-D-aspartate receptors by phencyclidine causes the loss of corticostriatal neurons. Neuroscience 125: 473-483.

Wangen K, Myhrer T, Moldstad JN, Iversen EG, Fonnum F (1997). Modulatory treatment of NMDA receptors in neonatal rats affects cognitive behavior in adult age. Brain Res Dev Brain Res 99: $126-130$.

Whitlock JR, Heynen AJ, Shuler MG, Bear MF (2006). Learning induces long-term potentiation in the hippocampus. Science 313: 1093-1097.

Wiedholz LM, Owens WA, Horton RE, Feyder M, Karlsson RM, Hefner $\mathrm{K}$ et al (2008). Mice lacking the AMPA GluR1 receptor exhibit striatal hyperdopaminergia and 'schizophrenia-related' behaviors. Mol Psychiatry 13: 631-640.

Yamasaki N, Maekawa M, Kobayashi K, Kajii Y, Maeda J, Soma M et al (2008). Alpha-CaMKII deficiency causes immature dentate gyrus, a novel candidate endophenotype of psychiatric disorders. Mol Brain 1: 6.

Yao WD, Gainetdinov RR, Arbuckle MI, Sotnikova TD, Cyr M, Beaulieu JM et al (2004). Identification of PSD-95 as a regulator of dopamine-mediated synaptic and behavioral plasticity. Neuron 41: 625-638.

Yeh SH, Mao SC, Lin HC, Gean PW (2006). Synaptic expression of glutamate receptor after encoding of fear memory in the rat amygdala. Mol Pharmacol 69: 299-308.

Zhu JJ, Qin Y, Zhao MM, Van Aelst L, Malinow R (2002). Ras and Rap control AMPA receptor trafficking during synaptic plasticity. Cell 110: 443-455. 